Int. J. Morphol.,

31(2):378-387, 2013.

\title{
Esqueleto Axial y Apendicular de Vertebrado
}

\author{
Axial and Appendicular Skeleton of Vertebrates
}

Ricardo Olivares* \& Mariana Rojas*,****

OLIVARES, R. \& ROJAS, M. Esqueleto axial y apendicular de vertebrados. Int. J. Morphol., 31(2):378-387, 2013.

RESUMEN: Los primeros componentes de las vértebras fueron los arcos dorsales (neural e interneural) y ventrales (hemal e interhemal) que se apoyaban en la notocorda; el siguiente paso fue la formación de dos centros (intercentro y pleurocentro), que sirvieron para fijar y dar soporte a los arcos. Muchos peces presentan costillas dorsales y ventrales. En las aves se reducen las costillas cervicales y se fusionan a las vértebras, las primeras costillas torácicas son flotantes y la mayoría de las verdaderas presentan procesos que permiten la fijación muscular y refuerzan las paredes torácicas. Los mamíferos presentan costillas en todas las vértebras torácicas, siendo la mayoría verdaderas. El esternón es una estructura de origen endocondral, los peces, tortugas, serpientes y muchos lagartos apodos, carecen de esternón. Las aves voladoras tienen un gran esternón provisto de una prominente quilla ventral. Desarrollo del esqueleto axial: La notocorda y la parte ventral del tubo neural expresan Sonic hedgehog $(\mathrm{SHH})$, que induce a la porción ventromedial del somita a transformarse en esclerotomo y a expresar el factor de transcripción PAX-1, que controla la formación de cartílago y hueso para que se constituyan las vértebras. El patrón de expresión de los genes Hox en vertebrados, es quien determina cuál es el tipo de estructura vertebral que se tiene que formar. El esqueleto apendicular comprende la cintura pectoral formada por elementos esqueléticos dérmicos y endocondrales, que sostiene la aleta pectoral y la cintura pélvica o caderas, formada sólo por elementos endocondrales, que sostienen la aleta pelviana. Los miembros anteriores y posteriores de los tetrápodos están construidos bajo el mismo patrón, diferenciándose tres regiones: autopodio, zeugopodio y estilopodio. Desarrollo del esqueleto apendicular: Se forma desde el mesodermo lateral somático y la cresta apical ectodérmica. El mesodermo lateral somático recibe células del miotomo y dermatomo para formar el esbozo de miembro.

PALABRAS CLAVE: Esqueleto; Vértebras; Costillas; Esternón; Anatomía comparada; Osteología comparada.

\section{ESQUELETO AXIAL}

La columna vertebral ofrece un lugar para la fijación de la musculatura regional, impide el acortamiento del cuerpo y soporta gran parte del peso de éste en los tetrápodos. Consiste en una serie repetida de elementos óseos o cartilaginosos separados, "las vértebras", cuya función original fue proteger a la médula espinal y la arteria. Los primeros componentes de las vértebras en aparecer fueron los arcos dorsales (neural e interneural) y ventrales (hemal e interhemal) que se apoyaban en la notocorda; el siguiente paso fue la formación de dos centros (intercentro y pleurocentro), que sirvieron para fijar y dar soporte a los arcos (Fig. 1). En los amniotas predomina el pleurocentro que se convierte en el cuerpo de cada segmento vertebral y el intercentro en su mayor parte, se convierte en el disco intervertebral (Fig. 1). (Kardong, 2005).
Los segmentos vertebrales que componen la columna axial tienden a estar diferenciados regionalmente, es así como, en la mayoría de los peces la columna vertebral se diferencia en una región precaudal y otra caudal (Fig: 2 a, b, c, d y e); la parte más anterior del tronco de los tetrápodos se diferencia en una región cervical (Fig. 2f) y la posterior en una región sacra, como también en algunos, encontramos una región torácica y lumbar (Fig. 2g) (Kardong).

Por otro lado, la forma de las superficies articulares de los extremos de los centros vertebrales, afectan la manera en como se distribuyen las fuerzas entre las vértebras. Es así como, los centros que tienen extremos aplanados son acélicos (mamíferos), si cada superficie es cóncava anficélicos (peces), anteriormente cóncavos y posteriormente

* Departamento de Ciencias Biológicas Animales, Facultad de Ciencias Veterinarias y Pecuarias, Universidad de Chile.

** Laboratorio de Embriología Comparada, Programa de Anatomía y Biología del Desarrollo, ICBM, Facultad de Medicina, Universidad de Chile.

**** Programa de Doctorado en Ciencias Morfológicas, Universidad de La Frontera, Temuco. 

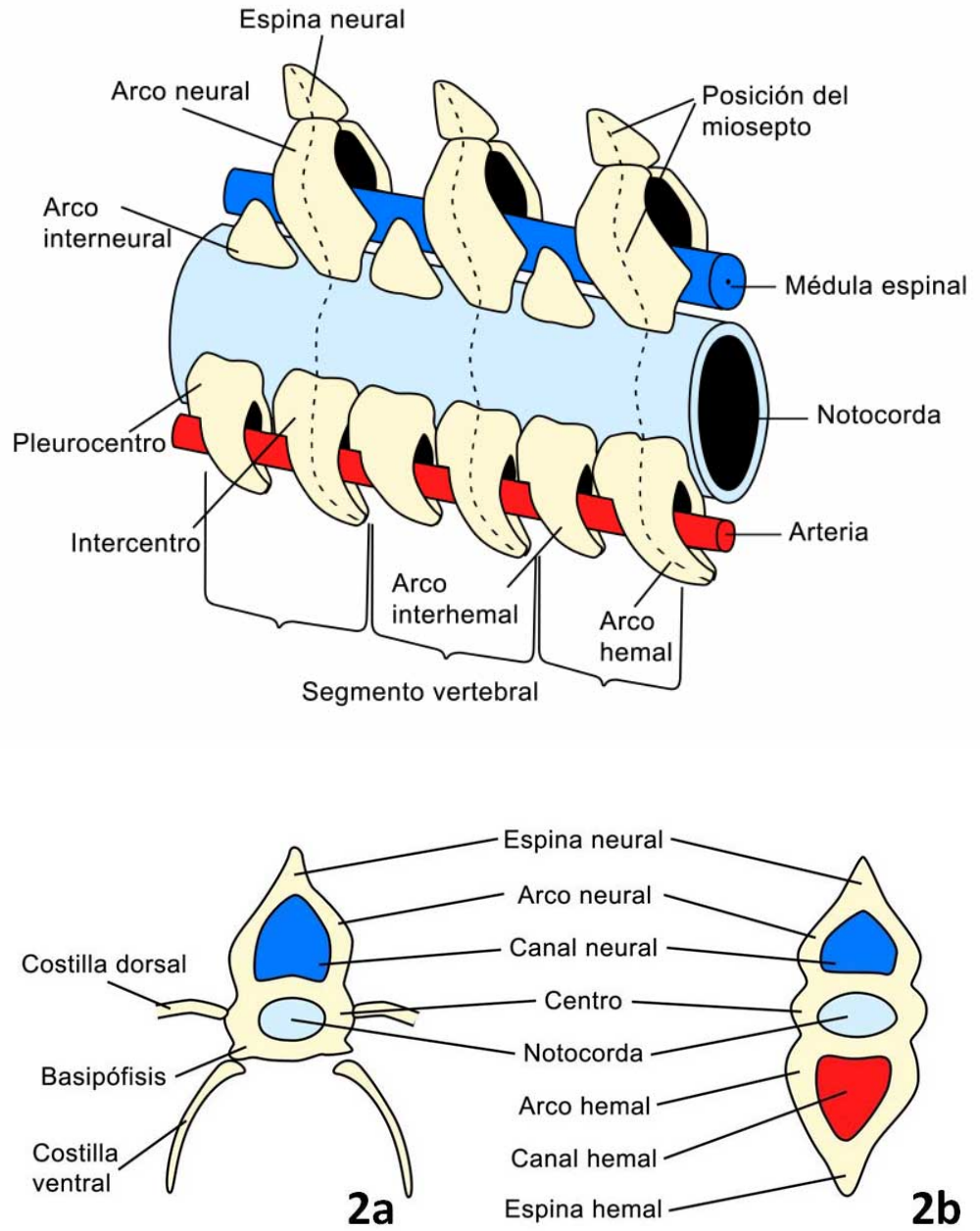

Fig. 1. Esqueleto axial de un vertebrado primitivo, se ilustran tres segmentos vertebrales y la notocorda. Los elementos vertebrales están representados por un par de centros (intercentro y pleurocentro), sus arcos vertebrales asociados, dorsales (neural e interneural) y ventrales (hemal e interhemal). Las líneas punteadas señalan la localización de los mioseptos (Modificado de Kardong, 2005).

Figs. 2 a y $2 \mathrm{~b}$ : Esquema que compara secciones transversales de una vértebra precaudal con una vértebra caudal, En la precaudal se observan costillas dorsales y ventrales, En la vértebra caudal se observa un canal neural y otro hemal (Modificado de Kardong, 2005).

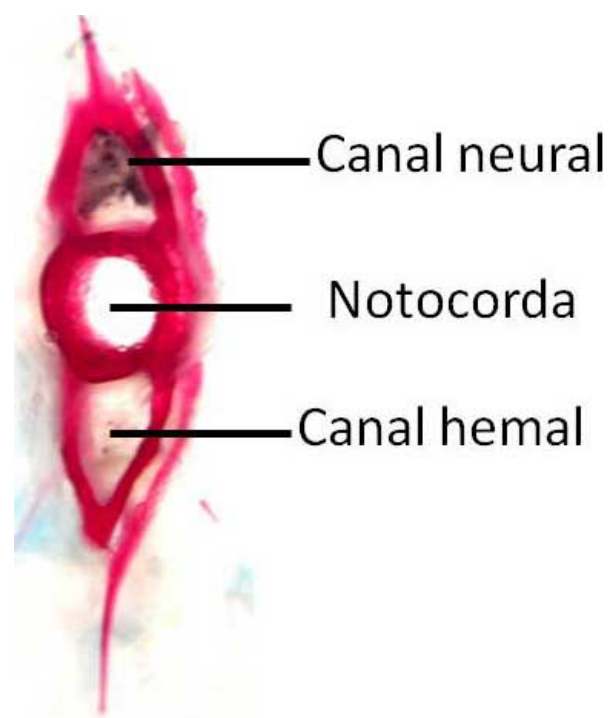

Fig. 2c. Sección transversal de la vértebra caudal de un salmón. Salmo salar. Presenta canal neural, hemal y un centro donde se ubica la notocorda. Técnica de Hanken y Wassersug.

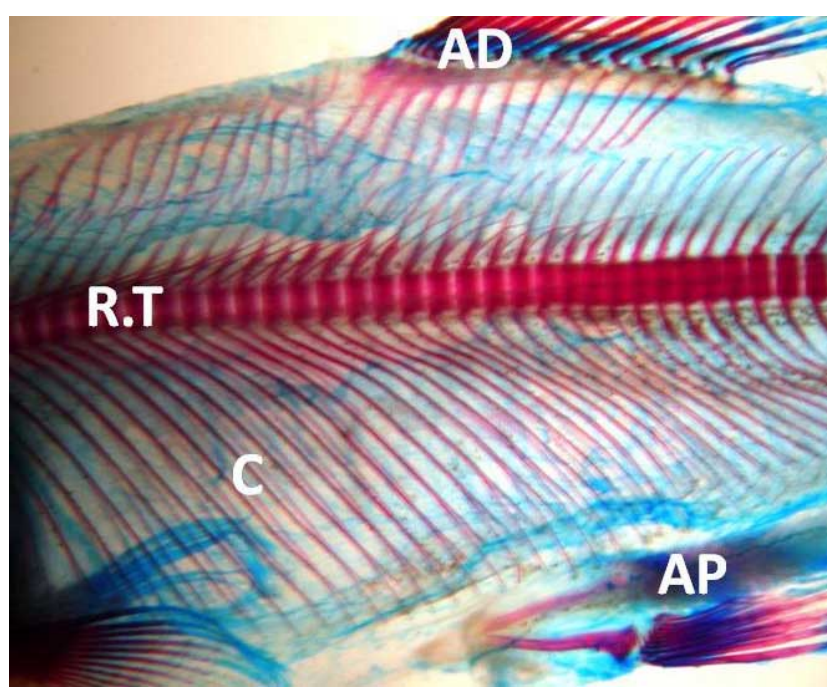

Fig. 2d. Región precaudal de salmón (RT) se observan costillas (C) además la aleta dorsal (AD) y aleta pélvica (AP). Técnica de Hanken y Wassersug. 


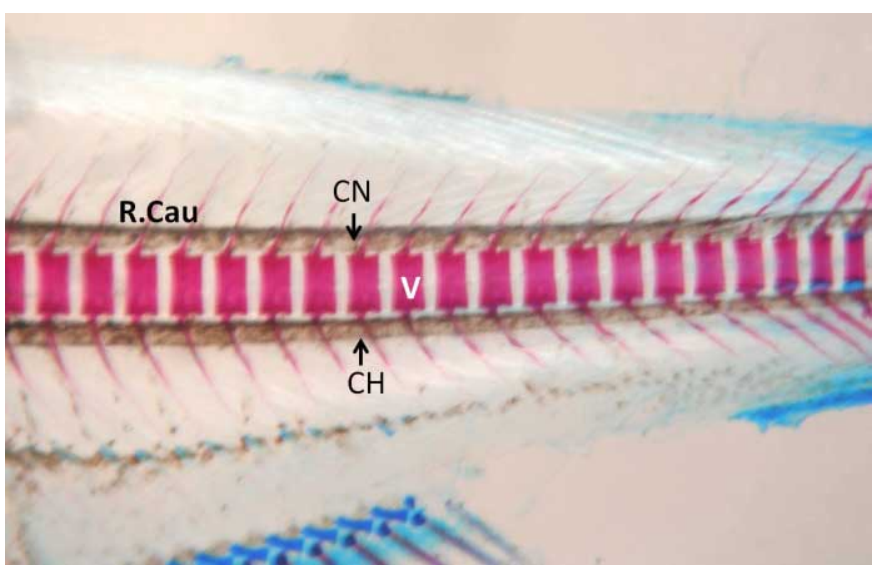

Fig. 2e. Región caudal (R.Cau) del esqueleto de salmón. Canal neural con médula espinal $(\mathrm{CN})$, cuerpos vertebrales $(\mathrm{V})$, canal hemal con vaso sanguíneo $(\mathrm{CH})$. Técnica de Hanken y Wassersug.
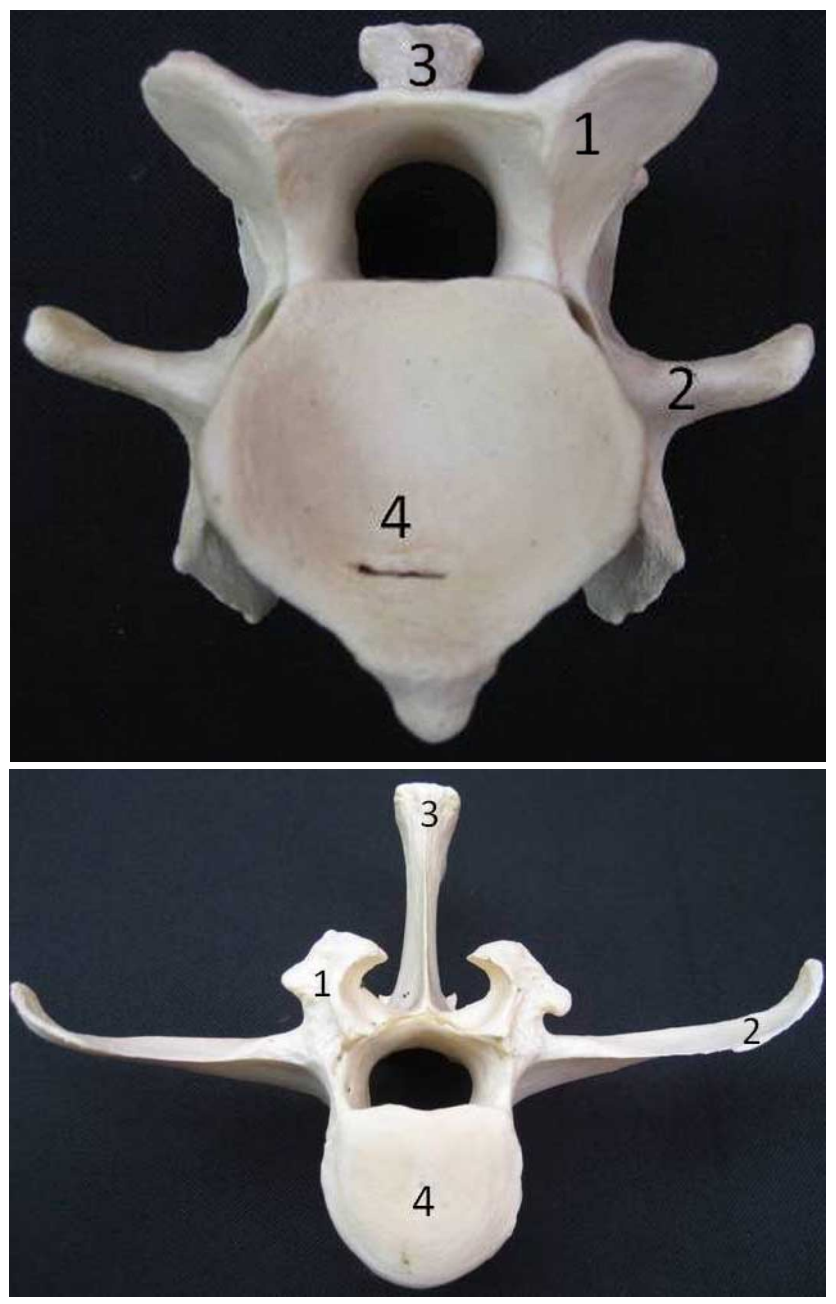

Fig. 2f. Vista caudal de una vértebra cervical de bovino y Figura $2 \mathrm{~g}$. Vista craneal de vértebra lumbar de bovino. Procesos articulares (1), Procesos transversos (2), Proceso espinoso (3), Cuerpo vertebral (4). Gentileza Dra. Patricia Labra, Directora Esqueletos Chile. convexos procélicos, la forma inversa opistocélicos (anfibios y reptiles) y los heterocélicos (aves), que presentan ambos extremos en forma de silla de montar (Fig. 3) (Romer, 1973).

Las costillas proporcionan lugares para la fijación muscular, ayudan a suspender el cuerpo, forman una caja protectora alrededor de las vísceras y sirven como mecanismo accesorio para la respiración. Se forman a partir del cartílago de los mioseptos, que dividen los bloques sucesivos de musculatura segmentaria del cuerpo. Muchos peces presentan en cada segmento vertebral costillas dorsales y ventrales. En los tetrápodos uno de estos grupos de costillas se pierde y el otro persiste. Las costillas de los tetrápodos primitivos son bicéfalas, la cabeza ventral (capítulo) se articula con el intercentro y la cabeza dorsal (tubérculo) con el arco neural (Figs. 4a y 4b). Su clasificación se basa en el tipo de asociación que establecen con el esternón directa (verdaderas), indirecta (falsas) o ninguna (flotantes). En las aves se reducen las costillas cervicales y se fusionan a las vértebras, las primeras costillas torácicas son flotantes y la mayoría de las verdaderas presentan procesos (uncinada), que permiten la fijación muscular y refuerzan las paredes torácicas. Los mamíferos presentan costillas en todas las vértebras torácicas, siendo la mayoría verdaderas (Fig. 4a) (Dyce et al., 1999, Kardong).

El esternón es una estructura esquelética medioventral, de origen endocondral. Puede estar formado por una única placa ósea (placa coracoides) o por varios elementos en serie (esternebras); los peces, tortugas, serpientes y muchos lagartos apodos, carecen de esternón. En las aves voladoras la masa de músculos del vuelo, se inserta en un gran esternón provisto de una prominente quilla ventral (carena) (Kardong) (Fig. 5). En los mamíferos a la primera y última esternebra se les denominan manubrio y xifoesternón, respectivamente, y a la región media mesoesternón (Dyce et al.).

Peces: En los peces agnatos existe una notocorda que proporciona el eje mecánico central del cuerpo. Con respecto a los gnatostomados, en los peces primitivos (condrictios), la notocorda proporciona el soporte axial y la columna vertebral sólo está representada por los arcos neurales y hemales de tejidos cartilaginosos. En los peces óseos más evolucionados (teleósteos), la columna vertebral está osificada y sus centros se relacionan con la notocorda como soporte mecánico principal del cuerpo (Castro et al., 2011) (Fig. 6). En los peces actinopterigios del orden Clupeidae, la columna vertebral está formada por las vértebras precaudales ( 9 a 11) y caudales (31 a 36). Las costillas están presentes desde la $4^{\mathrm{a}}$ vértebra precaudal hasta la vértebra 14-16 caudal (Segura 


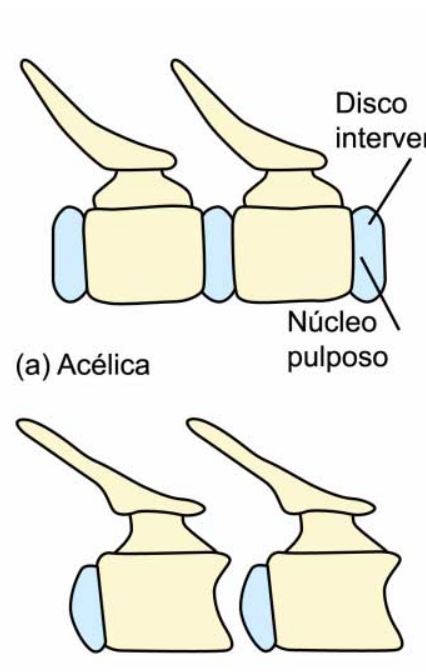

(c) Procélica

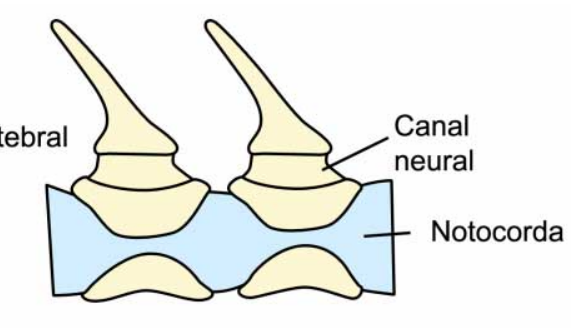

(b) Anficélica

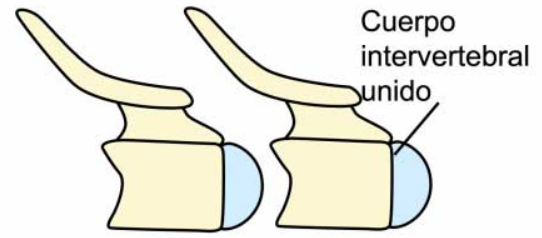

(d) Opistocélica

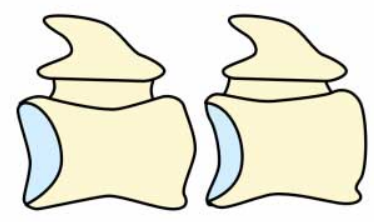

(e) Heterocélica

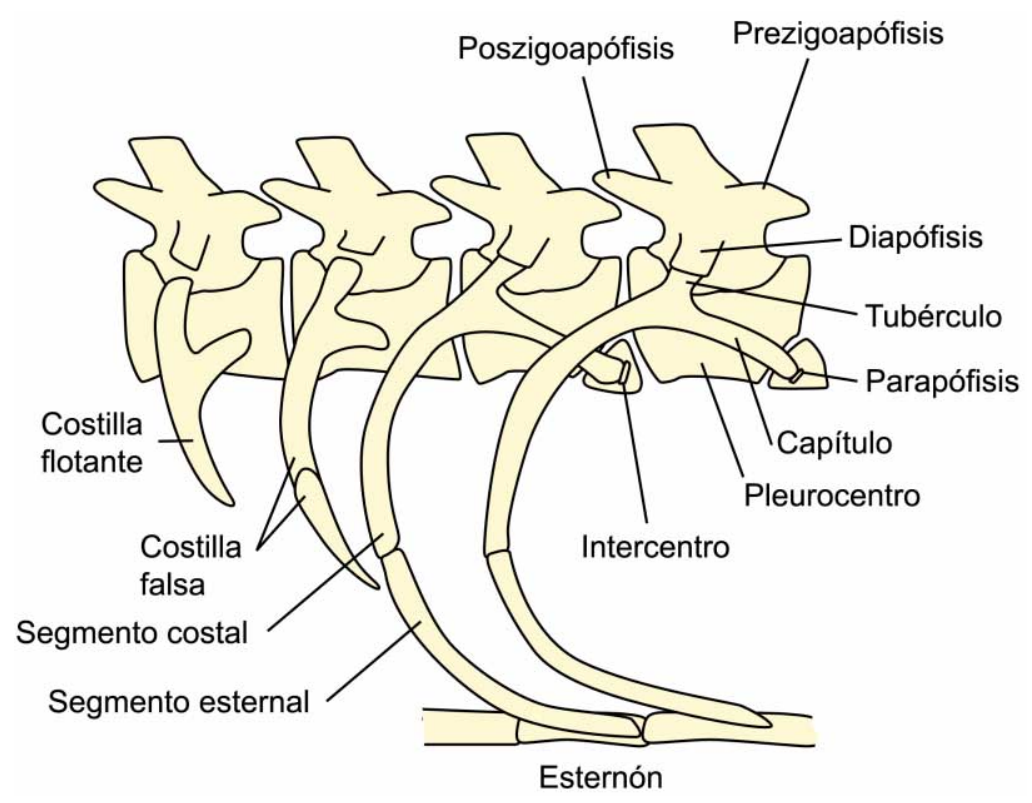

Fig. 4a: Costillas de los amniotas. Las costillas verdaderas se articulan con el esternón. Las costillas falsas con otras costillas y las costillas flotantes con nada. Originalmente las costillas tienen dos cabezas, capítulo y tubérculo, que se articulan con las parapófisis sobre el intercentro o las diapófisis sobre el arco neural, respectivamente. El cuerpo de la costilla puede diferenciarse en una parte dorsal o segmento vertebral, y una parte ventral o segmento esternal (Modificado de Kardong, 2005).

Fig. 3. Formas generales de los centros. Las formas de los extremos, definen tipos anatómicos específicos: a) acélico, extremos planos; b) anficélico, ambos extremos cóncavos; c) procélico, el extremo anterior es cóncavo; d) opistocélico, el extremo posterior es cóncavo; e) heterocélico, los extremos tienen forma de silla de montar (Modificado de Kardong, 2005).

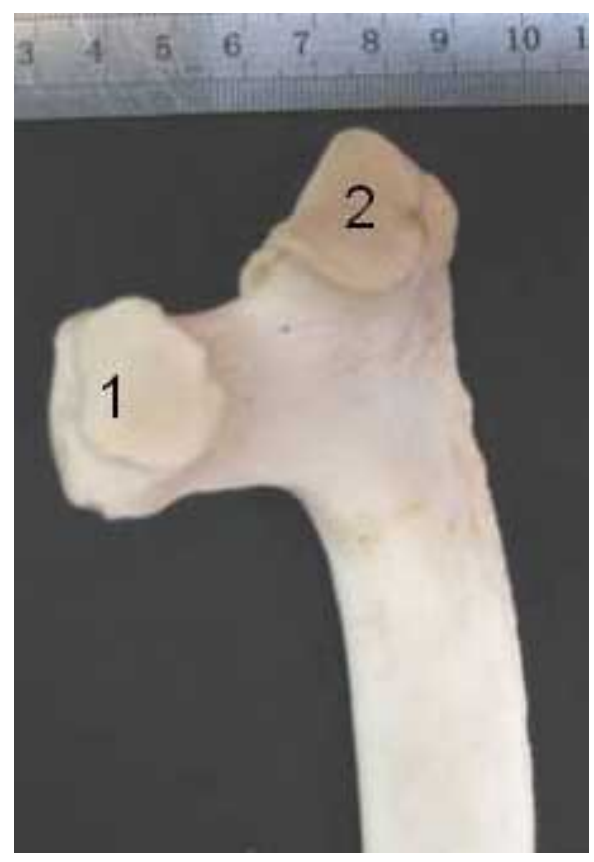

Fig. 4b: Costilla de bovino. Capítulo (1), tubérculo (2). Gentileza Dra. Patricia Labra, Directora Esqueletos Chile. 


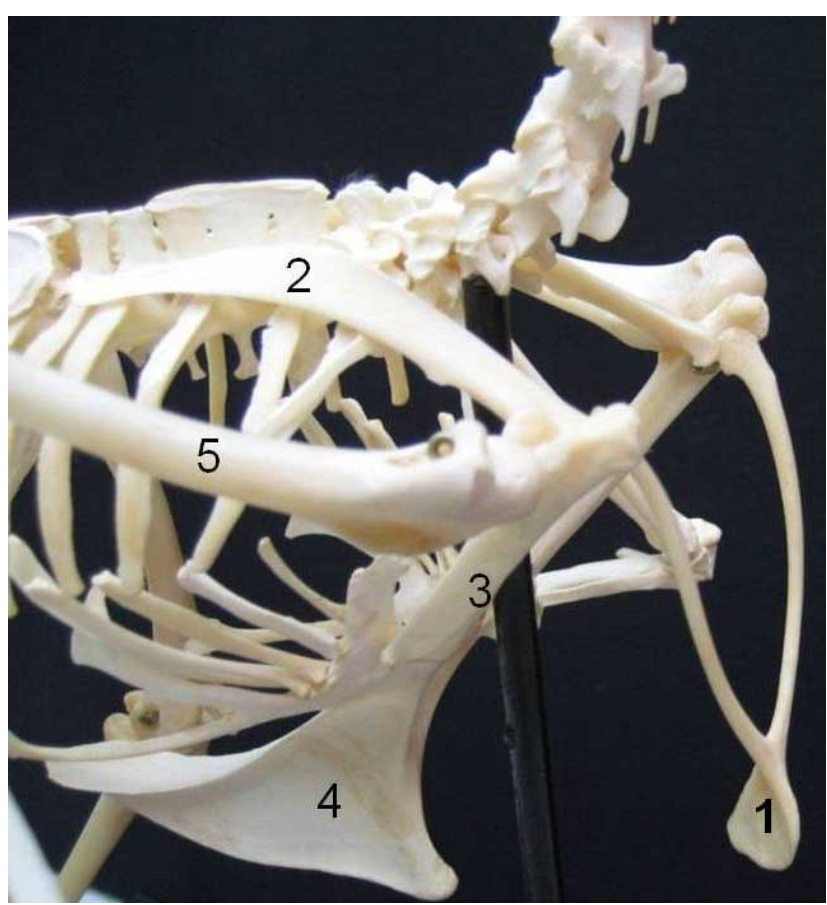

Fig. 5: Vista lateral de esqueleto de ave: Fúrcula (1), escápula (2), coracoides (3), esternón (4), húmero (5). Gentileza Dra. Patricia Labra Directora Esqueletos Chile.

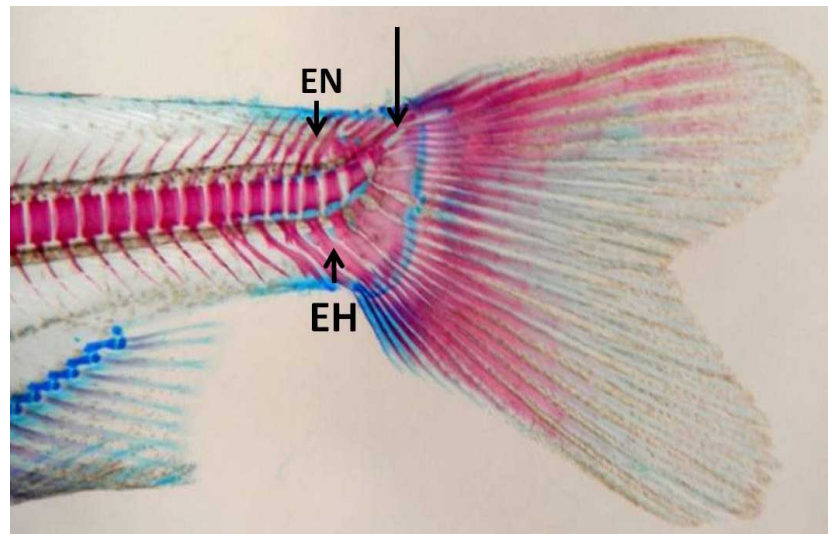

Fig. 6: Aleta caudal de salmón. La columna vertebral caudal se inclina hacia arriba (ver flecha), Se observan los arcos hemales (EH) y arcos neurales (EN).

\& Díaz de Astarloa, 2004); y en la familia Tripteerigiidae, se describen 10 vértebras precaudales y 31 caudales, encontrándose siempre que las primeras dos vértebras carecen de espina neural (Cancino et al., 2010).

El esqueleto axial de la mayoría de los peces se prolonga en la cola, donde puede adoptar diversas formas: heterocerca (condrictios), cuando el extremo posterior de la columna vertebral se introduce en el lóbulo dorsal de la cola; dificerca (peces pulmonados), cuando la columna vertebral se prolonga en forma recta y simétrica; y homocerca (teleósteos), en donde si bien los lóbulos de la cola parecen simétricos, la reducida columna vertebral caudal, se inclina hacia arriba, formando el soporte del extremo dorsal de la aleta (Romer) (Fig. 6). La evolución de la aleta caudal ha llegado a ser una importante herramienta sistemática. El esqueleto caudal del Syngnathus abaster adulto presenta un hueso hipural superior y uno inferior, ambos separados por un diastema hipural, definiendo los lóbulos superior e inferior de la aleta caudal. Los huesos hipurales son grandes y cortos ofreciendo una amplia superficie para la adherencia de los rayos caudales, Cinco rayos se conectan al hueso hipural superior y cinco al inferior; esto provee una cola simétrica homocerca no especializada con 10 radios. Los rayos lepidotricos no son ramificados y sólo en adultos son segmentados (Bartolino, 2005). Los peces teleósteos Achirus lineatus y A. mazatlanus se caracterizan por una fórmula caudal compuesta por 1 hueso epural +5 hipurales +1 parahipural, además de una espina neural y dos espinas hemales; así como por la presencia de 16 radios principales. (Gracian-Negrete et al., 2012).

Anfibios: De la radiación de los labirintodontos (fósiles), aparecieron dos líneas que se caracterizaron por las diferencias en la importancia relativa de cada centro vertebral. La línea temnospóndila, en la cual predomina el intercentro y la antracosauria en la cual predomina el pleurocentro. En ambos casos, la notocorda se reduce y los respectivos centros vertebrales asumen el papel central en el soporte axial. La consecuencia del alargamiento de un centro a expensas de otro, disminuyó la flexibilidad, consolidó la columna axial y por lo tanto, aumentó su capacidad para soportar el peso del cuerpo sobre la tierra. Otra característica nueva del esqueleto axial, que aparece por primera vez en los anfibios, es la delimitación de la región sacra (Kardong).

En las ranas del género Telmatobufo, como también en la rana austral chilena (Eupsophus coppingeri) el atlas y el axis están fusionados y la columna vertebral tiene ocho vértebras presacrales del tipo procélicas (Formas et al., 2001, 2008). Entre los anuros adultos, la columna vertebral consiste en no más de 9 vértebras presacrales, una vértebra sacral y postsacralmente el urostilo, el cual caracteriza a todos las ranas y sapos y que aporta superficie de inserción para los músculos que permiten la extensión simétrica de los miembros posteriores durante el salto (Handrigan \& Wassersug, 2007).

Amniotas: Filogenéticamente, los amniotas reciben sus vértebras de la línea antracosauria. En las serpientes, donde las fuerzas de giro pueden ser potentes, por carecer de miembros, existen zigapófisis (procesos articulares), las que proporcionan una resistencia adicional a la torsión. Por otro lado las aves presentan numerosas vértebras cervicales 
heterocélicas, muy móviles, que proporcionan al cráneo, una gran libertad de movimiento y extensión; en el otro extremo, las vértebras torácicas posteriores, lumbares y sacras, se fusionan en una unidad, el sinsacro (Fig. 7). A su vez, los huesos de la cintura pélvica fusionados (hueso innominado), se fusiona con el sinsacro, conformando una estructura firme pero ligera, que sostiene al cuerpo durante el vuelo (Kardong). (Fig. 7).

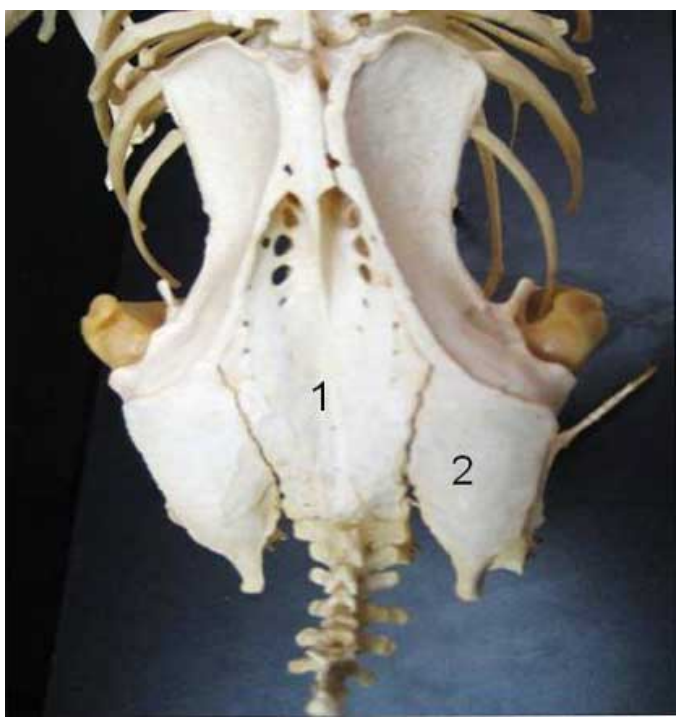

Fig. 7. Vista dorsal de esqueleto de ave. Sinsacro (1), hueso innominado (2). Gentileza Dra Patricia Labra, Directora Esqueletos Chile.

La columna vertebral de los mamíferos está diferenciada en distintas regiones, existiendo siete vértebras cervicales (salvo excepciones), las tóraco-lumbares varían entre 15 a 20 y las sacras de 2 a 5 , y el número de las caudales es variable (Kardong). En relación a los mamíferos acuáticos, en delfines (Lagenodelphis hosei), se describe un rango de 78 a 81 vértebras, encontrándose el atlas y el axis fusionados por sus cuerpos. Además, en promedio, se constata la presencia de 15 pares de costillas, de los cuales 5 son bicípitas (Lucero et al., 2009).

Desarrollo del esqueleto axial. La columna vertebral y las costillas se forman desde los somitos. La notocorda y la parte ventral del tubo neural expresan la proteína Sonic hedgehog (SHH), que induce a la porción ventromedial del somita a transformarse en esclerotomo y a expresar el factor de transcripción PAX-1, que controla la formación de cartílago y hueso para que se constituyan las vértebras. Las proteínas WNT también inducen la parte dorsomedial del somito a diferenciarse en las células precursoras de los músculos y a expresar el gen específico del músculo MYF5 y que se for- men los precursores de la musculatura de la columna vertebral (Fig. 8) (Sadler, 2010). El patrón de expresión de los genes Hox en vertebrados es quien determina cuál es el tipo de estructura vertebral que se tiene que formar. De esta manera el establecimiento ordenado de las vértebras (cervical, torácica, lumbar, sacra y caudales), depende de la expresión de los genes Hox quienes especifican la identidad posicional a lo largo del eje anteroposterior. Las vértebras torácicas comienzan en el somito 20 en el pollo y en el somita 12 en el ratón, esto se debe a que los límites anteriores de expresión génica de Hoxc5 y Hoxc 6 tanto en el pollo como en el ratón se localizan en el límite cérvico torácico, Hoxc 8 se expresa en la región torácica. Hoxd 9 y Hoxd10 se expresan en la transición de las regiones lumbar y sacra. Los genes Hox más posteriores son Hoxd 12 y Hoxd 13, los cuáles se expresan en la cola postnatal que se desarrolla después (Wolpert, 2009). Llama la atención que en los vertebrados tetrápodos, la expresión de Hoxb5 y Hoxc8 están restringidas a una región muy corta del tronco. En cambio en el embrión de reptiles como pitón, cascabel y otras, estos genes se expresan a lo largo de todo el cuerpo hasta el rudimento pelviano, debido a esto se forman varios cientos de costillas expandiéndose el segmento torácico.

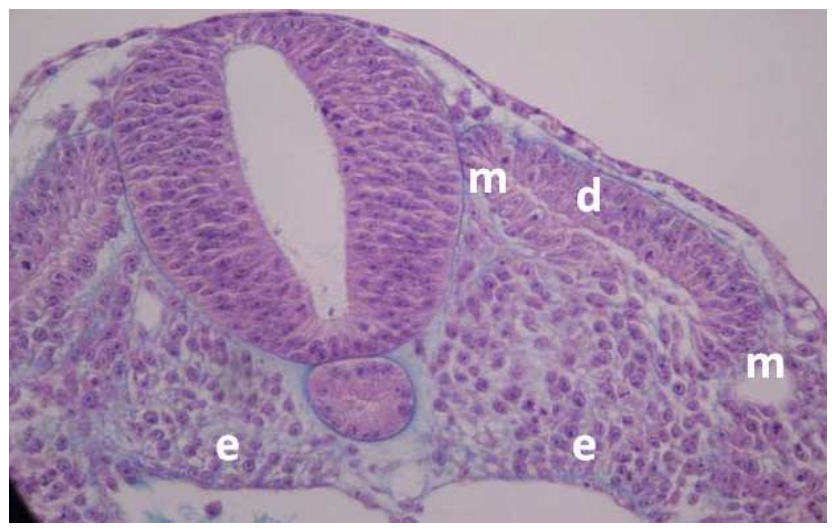

Fig. 8. Embrión de pollo. El somito se ha diferenciado en esclerotomo (e) miotomo (m) y dermatomo (d). El esclerotoma forma huesos y cartílagos de la columna vertebral, y desde el miotomo se diferenciará su musculatura estriada.

\section{ESQUELETO APENDICULAR}

El esqueleto apendicular comprende la cintura pectoral, formada por elementos esqueléticos dérmicos y endocondrales, que sostiene la aleta pectoral o miembro anterior; y la cintura pélvica o caderas, formada sólo por elementos endocondrales, que sostienen la aleta pelviana o miembro posterior (Kardong). Las aletas están constituídas por radios dérmicos, que se originaron como elementos 


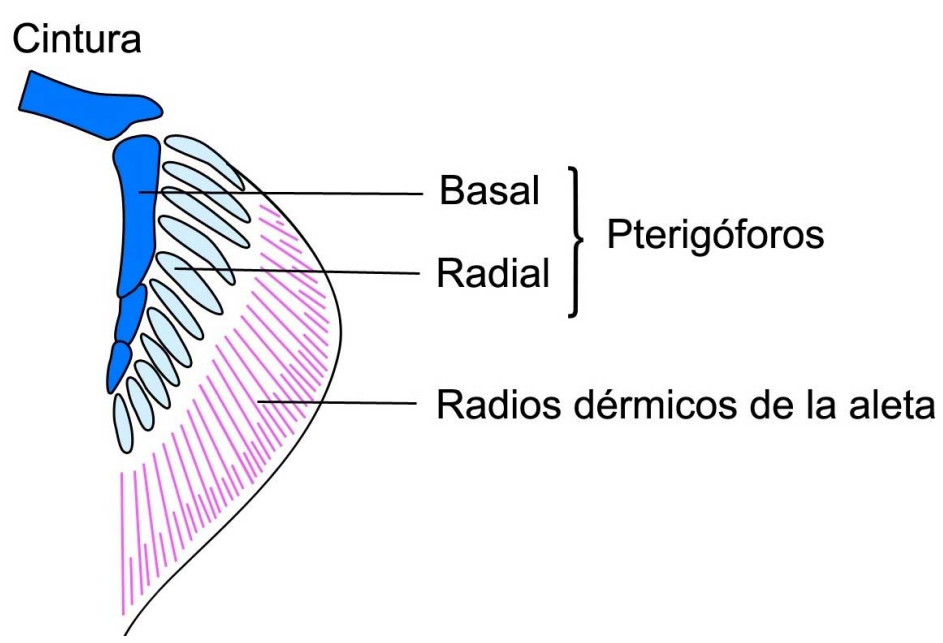

Fig. 9a: Componentes básicos de la aleta. La aleta se compone de pterigóforos basales, radiales, y de radios dérmicos (Modificado de Kardong, 2005).

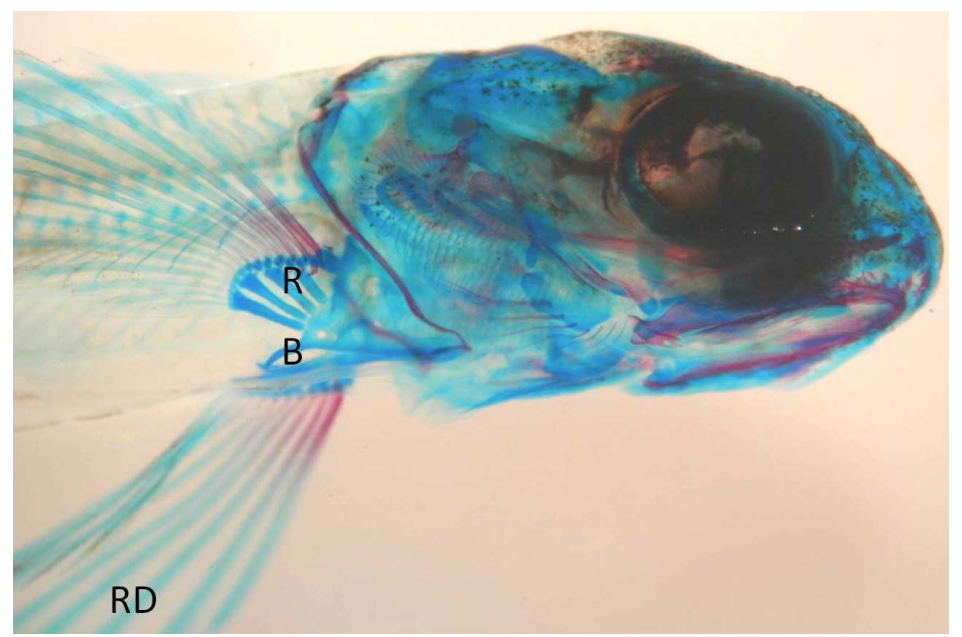

Fig. 9b: Visión lateral de esqueleto de salmón. Se observa radios dérmicos de la aleta $(\mathrm{RD})$, pterigóforos radiales $(\mathrm{R})$ y pterigóforos basales (B).

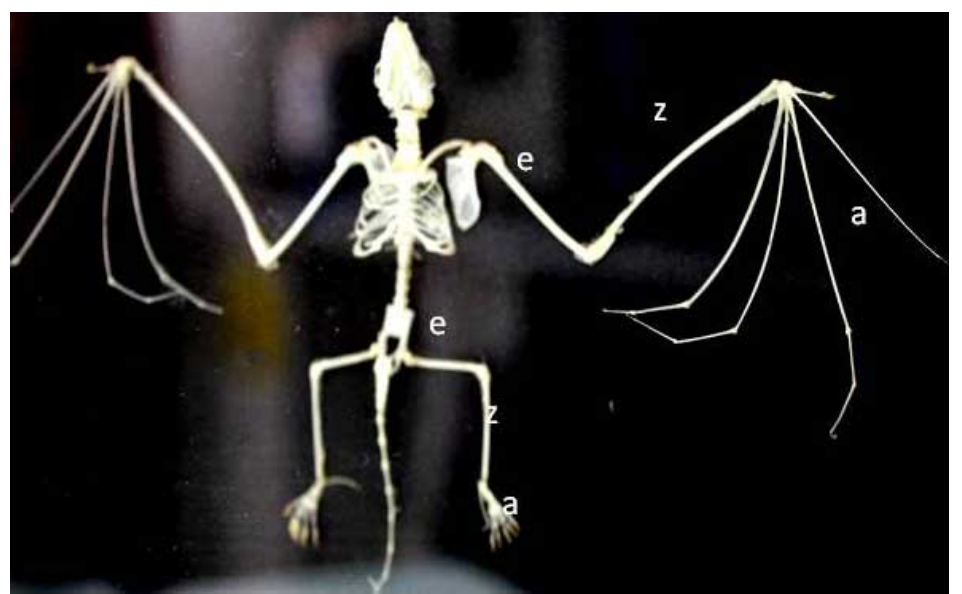

Fig. 9c: Componentes básicos de los miembros de un murciélago, estilopodio (e) zeugopodio (z) y autopodio (a). Museo de Embriología Comparada. Fac. de Medicina. Universidad de Chile estabilizadores y de avance del cuerpo del pez. La parte proximal de la aleta, junto al cuerpo, está sostenida por pterigóforos de dos tipos: basales y radiales, que articulan a las aletas pectorales y pelvianas, con las cinturas respectivas. (Figs. 9a y b). Los miembros anteriores y posteriores de los tetrápodos están construidas bajo el mismo patrón, diferenciándose tres regiones de distal a proximal: autopodio, zeugopodio y estilopodio, respectivamente (Fig. 9c) (Kardong).

Peces: Los primeros gnatostomados (acantodios y placodermos), poseían dos juegos de aletas pares (pectorales y pelvianas). Los condrictios primitivos, tenían aletas pectorales y pelvianas que fundamentalmente eran estabilizadoras; en los tiburones posteriores, los componentes basales pares de ambas cinturas, se alargaron hacia la línea media para fusionarse en el escapulocoracoides y las barras pubioisquiales, respectivamente. La cintura pectoral de los actinopterigios es parcialmente endocondral, si bien la mayor parte es dérmica, esta última se encuentra bien establecida incluso en los peces óseos primitivos (Kardong). En la Saraca (Brevoortia aurea), la cintura escapular está constituída por el postemporal, el cual une la cintura escapular al cráneo por medio de los supracleitra, cleitrum, coracoides, mesocoracoides, la escápula, tres series de radiales pectorales y supracleitrum y dos poscleitra; por otro lado, la cintura pélvica está formada por un par de basipterigios y por dos o tres pequeños radiales pélvicos (Segura \& Díaz de Astarloa). Entre los sarcopterigios, presenta un interés particular los crosopterigios, porque las aletas de estos peces primitivos tienen ciertas características que las aproximan a las de los miembros de los mamíferos primitivos (Kardong).

Tetrápodos: Los primitivos anfibios, rápidamente mostraron cambios en el esqueleto apendicular correlacionado con la locomoción terrestre y la explotación de este medio. Es así como, la cintura pectoral tendió a perder su fijación al cráneo, cinturas y miembros se hicieron más fuertes, robustos y osificados. Su cintura pelviana estaba formada por tres huesos fusionados: pubis, isquion e ilion, por medio de este último, la cintura pelviana se fijó a la columna vertebral (región sacra) y las aletas dérmicas de los peces antecesores se sustituyeron por dedos. Puesto que la cintura pectoral no está conectada con la parte posterior del cráneo, se pierde la serie dorsal de huesos dérmicos (postemporal, supracleitro, anocleitro y postcleitro). En los anfi- 
bios modernos, por lo general, se pierden por completo los huesos dérmicos (salamandras), o se reducen en altura (anuros). En los reptiles primitivos persisten la clavícula y la interclavícula, pero generalmente no hay cleitro. En las aves el par de clavículas generalmente se fusionan con la interclavícula impar, dando lugar a un hueso compacto, la fúrcula (Fig. 5). Los dos coracoides están presentes en los pelicosaurios (reptiles con velas dorsales), terápsidos (reptiles y mamiferoides) y monotremas, pero solamente el coracoides (el posterior), queda en los marsupiales y mamíferos placentados. Los terápsidos y monotremas tienen clavícula e interclavícula, pero los marsupiales y placentarios carecen de interclavícula. En los mamíferos, la clavícula tiene un desarrollo variable en las distintas especies, de acuerdo al tipo de locomoción y movimientos de coordinación de los miembros anteriores. Así, en mamíferos que cavan, trepan o vuelan, la clavícula alcanza gran longitud, en cambio es reducida en animales que se apoyan y desplazan sobre sus 4 miembros. El grado de desarrollo y complejidad de la clavícula varía, siendo máximos en el hombre, en cambio en el perro y gato es un hueso vestigial, afuncional y no articulado y no existe en ovinos y felinos adultos (Rojas \& Montenegro, 1994; 1995; Montenegro et al, 2004)

La cintura pelviana nunca está unida por aportaciones de hueso dérmico. Desde su primera aparición en los placodermos, dicha cintura es exclusivamente endoesquelética. En los crosopterigios, la cintura pelviana está formada por un único elemento, pero en los tetrápodos lo está por tres huesos endocondrales. Finalmente, en el extremo de cada miembro de los tetrápodos, el autopodio ha sufrido una evolución compleja. Hay varios dedos, comenzando cada uno en la parte proximal con un elemento metapodial (metacarpos y metatarsos, respectivamente), seguido de una cadena de falanges. Los dedos descansan sobre varios huesos separados (carpo y tarso, respectivamente). En algunos vertebrados marinos, la tendencia principal ha sido hacia la polifalangia, por otro lado, es poco frecuente encontrar especies actuales con más de cinco dedos (polidactilia) (Caldwell, 2002; Kardong). La fórmula de las falanges de las especies del género Telmatufo y en Eupsophus coppingeri es 2-2-3-3 en la mano y 2-2-3-4-3 en el pie (Formas et al., 2001, 2008).

Desde un punto de vista biomecánico, en los tetrápodos primitivos los miembros estaban colocados lateralmente en una posición extendida, estableciendo puntos de pivote. Muchos tetrápodos han desarrollado miembros girados bajo su cuerpo, aumentando de esta manera la facilidad y eficacia de una locomoción rápida. Esto conllevó también a una disminución de las masas musculares aductoras, con una concomitante reducción del tamaño del pubis e isquion. De igual forma en la cintura torácica, la posición de los miembros anteriores por debajo de la escápula, confirió a este hueso un mayor rol en la locomoción y sostenimiento del peso. Complementariamente, otras adaptaciones a la locomoción rápida fueron, el alargamiento de los miembros (de plantígrados a digitígrados) y la disminución de las masas musculares y número de dedos. Caso especial reviste la locomoción aérea, especialmente en las aves, en donde se verifican adaptaciones tales como, aumento del segmento mano en las aves muy voladoras y antebrazo en las planeadoras, la presencia de huesos neumáticos y un esternón extendido para la inserción de los potentes músculos del vuelo (Kardong).

\section{Desarrollo embrionario del esqueleto apendicular.}

La posición de los miembros en los costados del embrión a lo largo del eje craneocaudal está regulado por los genes HOX. El límite de expresión craneal del gen HOXB8 se encuentra en el borde craneal de las miembros superiores. El crecimiento de los miembros lo inician TBX5 en los miembros superiores, TBX4 en los miembros inferiores secretadas por las células del mesodermo lateral somático. Los cartílagos y huesos de los miembros se forman en el mesénquima del mesodermo lateral somático, la musculatura en cambio proviene del miotomo del mesodermo somítico. (Antonelli et al., 2012).

La pérdida de los miembros es bastante común (Fig. 10). Es así como las serpientes evolucionaron desde los lagartos y parecen haber perdido sus miembros en dos etapas. Se han encontrado fósiles de serpientes con miembros pos-

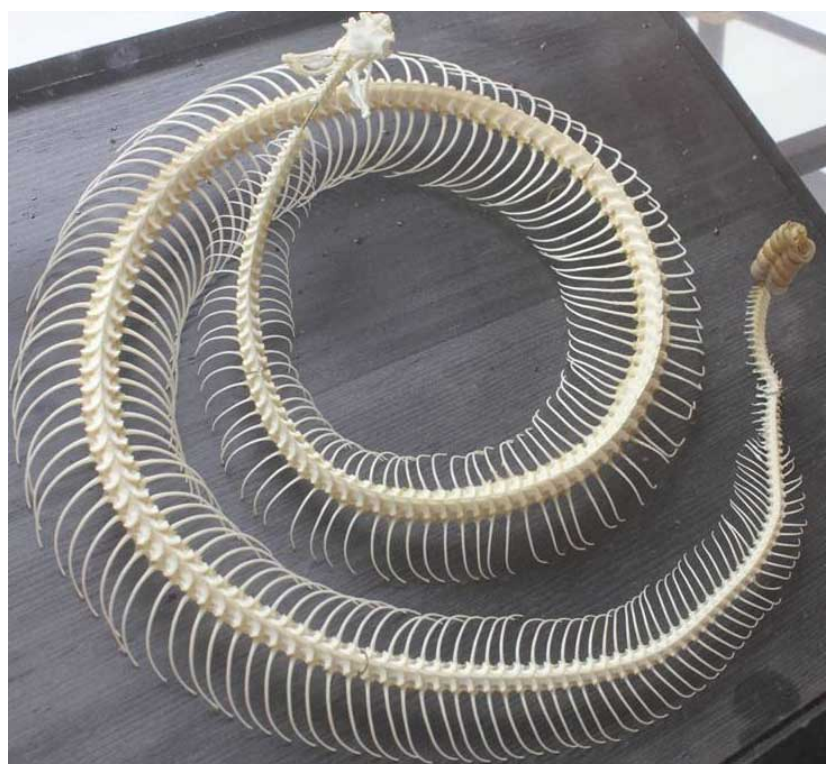

Fig. 10. Esqueleto de una serpiente cascabel. Se observan costillas a lo largo de prácticamente todo el cuerpo, no hay rudimentos de miembros. Museo de Embriología Comparada. Fac. de Medicina. Universidad de Chile. 
teriores, pero sin miembros anteriores. Además, las más primitivas como la boa y pitones tienen fajas pélvicas y fémures rudimentarios. La expresión del gen Hox se ha expandido a lo largo del eje corporal en embriones de pitón y esto lleva a la ausencia de miembros y a la expansión del segmento torácico en el esqueleto axial (Cohn \& Tickle, 1999). En estos animales, se forman los esbozos de miembros, pero las señales de la cresta apical y la zona de actividad polarizante no se activan.

Si se compara el miembro anterior de un murciélago con el de un caballo, se aprecia que aunque ambos conservan el patrón básico de los huesos, en el murciélago el miembro está adaptado para volar: los dedos se han alargado en gran medida a fin de sustentar un ala membranosa (Fig. 9). En el caballo, los miembros están adaptados para la carrera: en los anteriores los dedos laterales son reducidos, el metacarpo central aumenta de longitud y el radio y ulna se fusionan de modo que soportan una tensión mayor (Wolpert).
Otros huesos como la clavícula se forman transitoriamente en algunas especies de mamíferos tales como ovinos y luego involucionan en el período fetal, en cambio, en el gato se mantiene con pocos cambios. Ninguna de las dos especies desarrolla cartílagos secundarios. Si bien ambas tendrían información genética para desarrollar este carácter, su aparición heterocrónica en relación a las especies claviculadas, sumado a la falta de formación de cartílagos secundarios serían responsables de la involución que la lleva a mantener una presencia vestigial en gato o su regresión definitiva en ovinos (Rojas \& Montenegro).

En anatomía comparada se han realizado estudios descriptivos entre los componentes del esqueleto axial y apendicular de las diferentes especies. Aversi-Ferreira (2009), ha propuesto un nuevo método estadístico para la comparación entre las muestras de las estructuras de la misma especies y entre diferentes especies para suplir la falta de un método específico para el trabajo estadístico comparativo que sería de interés utilizar en futuras investigaciones.

OLIVARES, R.; ROJAS, M. Axial and Appendicular Skeleton of Vertebrates. Int. J. Morphol., 31(2):378-387, 2013.

SUMMARY: The first components of the dorsal vertebrae, were arches (neural and interneural) and ventral (haemal and interhemal) that relied on the notochord, the next step was the formation of two centers (intercentro and pleurocentro), which served to fix and support the arches. Many fish have dorsal and ventral ribs. In birds cervical ribs are reduced and vertebrae are fused, the first thoracic ribs are floating and the majority present processes allowing muscle fixation and reinforce the chest wall. Mammals have ribs on all thoracic vertebrae, the majority are true. The sternum is a structure of endochondral origin, fish, turtles, snakes and lizards have no sternum. Airborne fowl are provided with a large sternum prominent ventral keel. Development of the axial skeleton: The notochord and ventral neural tube express Sonic hedgehog ( $\mathrm{SHH}$ ) that induces the ventromedial portion of somite to become sclerotome and express the transcription factor Pax-1, which controls the formation of cartilage and bone that constitute the vertebrae. The expression pattern of Hox genes in vertebrates is what determines which type of vertebral structure is to be formed. The appendicular skeleton comprises the pectoral girdle consists of dermal and endochondral skeletal elements, holding the pectoral fin and pelvic girdle, consisting only endochondral elements that sustain pelvic fin. The forelimbs and hindlimbs of tetrapods are built on the same pattern, differing in three regions: autopod, zeugopod and stylopod. Appendicular skeletal development: Is formed from somatic lateral mesoderm and the apical ectodermal ridge. The lateral mesoderm receives somatic myotome and dermatome cells to form the outline member.

KEY WORDS: Skeleton; Vertebrae; Ribs; Sternum; Comparative anatomy; Comparative osteology.

\section{REFERENCIAS BIBLIOGRÁFICAS}

Antonelli, M.; Rosas, C. \& Rojas, M. Desarrollo de los miembros en los vertebrados. Int. J. Morphol., 30(4):1512-9, 2012.

Aversi-Ferreira, T. A. A new statistical method for comparative anatomy. Int. J. Morphol., 27(4):1051-8, 2009.

Bartolino, V. Skeletal organization of caudal fin in Syngnathus abaster (Osteichthyes, Syngnathidae). Int. J. Morphol., 23(4):305-8, 2005.

Caldwell, M.W. From fins to limbs to finds: Limb evolution in fossil marine reptiles. Am. J. Med. Genet., 112:236-49, 2002.
Cancino, C.; Farías, K.; Lampas, S.; González, B. \& Cuevas, V. Descripción de los complejos estructurales óseos en Helcogrammoides chilensis (Blennioidei: Tripterygiidae) de la zona central de Chile. Rev. Biol. Mar. Oceanogr., 45, S1:671$82,2010$.

Castro, S. R.; Bustos-Obregón, E. \& Rojas R. M. Vertebral column deformity and hypoxia in Salmo salar. Int. J. Morphol., 29 (4):1291-5, 2011.

Cohn, M. J. \& Tickle, C. Developmental basis of limblessness and axial patterning in snakes. Nature, 399:474-9, 1999. 
Dyce, K.M.; Sack, W.O. \& Wensing, C.J.G. Anatomía Veterinaria. $2^{\mathrm{a}}$ Ed. Buenos Aires, McGraw-Hill Interamericana.1999, 952pp.

Formas, J. R.; Núñez, J. J. \& Brieva, L.M. Osteología, taxonomía y relaciones filogenéticas de las ranas del género Telmatobufo (Leptodactylidae). Rev. Chil. Hist. Nat., 74:365-7, 2001.

Formas, J. R.; Núñez, J. \& Cuevas, C. Identidad de la rana austral chilena Eupsophus coppengeri (Amphibia, Anura, Neobatrachia): evidencias morfológicas, cromosómicas y moleculares. Rev. Chil. Hist. Nat., 81:3-20, 2008.

Gracian-Negrete, J. M.; González-Acosta, A. F.; González-Isáis. M.; Ortiz-Galindo, J. L. \& Del Moral-Flores, L. F. Osteología comparada del esqueleto caudal de Achirus lineatus y Achirus mazatlanus (Pleuronectiformes:Achiridae). Int. J. Morphol.,30(2):705-8, 2012.

Handrigan, G. R. \& Wassersug, R.J. The metamorphic fate of supernumerary caudal vertebrae in South Asian litter frog (Anura: Megophryidae). J. Anat., 211: 271-279, 2007.

Kardong, K.V. Vertebrados, Anatomía Comparada, Función, Evolución. McGraw-Hill Interamericana, Segunda Edición. 2005, 732pp.

Lucero, S. O.; Buono, M.R.; Castello, H.P. \& Junin, M. Análisis osteológico de ejemplares delfín de Fraser (Lagenodelphis hosei Fraser, 1956) provenientes de la costa de la provincia de Buenos Aires, Argentina. Rev. Biol. Mar. Oceanogr., 44(1):2334, 2009.

Montenegro, M. A.; Rojas, M. \& Domínguez, S. Osteogénesis comparativa de los cartílagos secundarios de la clavícula y placas epifisarias de los huesos largos. Int. J. Morphol., 22(3):201206, 2004.

Romer, A. S. Anatomía Comparada de Vertebrados. $4^{\mathrm{a}}$ ed. Buenos Aires, Interamericana 1973. p425.

Rojas, M. \& Montenegro, M.A. Embriogénesis del área clavicular en la oveja (Ovis aries) y gato (Felis catus). Rev. Chil. Anat., 12:5-11, 1994.

Rojas, M. \& Montenegro, M.A. An anatomical and embryological study of the clavicle in cats (Felis domesticus) and sheep (Ovis aries) during the prenatal period. Acta Anat., 154:128-34, 1995.

Segura, V. \& Díaz de Astarloa, J. M. Análisis osteológico de la saraca Brevoortia aurea (Spix) (Actinopterygii: Clupeidae) en el Atlántico suroccidental. Rev. Biol. Mar. Oceanogr., 39(2):37$52,2004$.

Sadler, T. W. Embriología Médica. $11^{\circ}$ ed. Wolters Kluwer, Lippincott Williams \& Wilkins 2010, 414 pp.

Wolpert, L. Principios del Desarrollo. $3^{\mathrm{a}}$ ed. Panamericana, Madrid, 2009, $552 \mathrm{pp}$.

\author{
Dirección para Correspondencia: \\ Dr. Ricardo Olivares Pérez Montt \\ Departamento de Ciencias Biológicas Animales \\ Facultad de Ciencias Veterinarias y Pecuarias \\ Universidad de Chile \\ Santiago \\ CHILE
}

Email: rolivare@uchile.cl

Recibido : 20-01-2013

Aceptado: 22-02-2013 